\title{
Clinical Characteristics in U19 Elite Soccer Players, Implications on Injury Prevention
}

\author{
Luis Llurda-Almuzara ${ }^{1,2, *}$, Albert Pérez-Bellmunt ${ }^{1, *}$, Carlos López-de-Celis ${ }^{3}$, Ramón Aiguadé ${ }^{4}$, Oriol Casasayas ${ }^{1}$ \\ Raul Navarro $^{1}$, Mathias Simon ${ }^{1}$, Olivier Peillon ${ }^{1}$ and Sara Ortiz-Miguel ${ }^{1}$ \\ 1. Anatomy Unit of Universitat Internacional de Catalunya, Barcelona (08195), Spain \\ 2. Medical Services of Damm FC, Barcelona (08031), Spain \\ 3. Physiotherapy Deparment of Universitat Internacional de Catalunya, Barcelona 08195, Spain \\ 4. Physiotherapy Department, Universitat de Lleida, Lleida (25006), Spain \\ *. Equal contribution
}

\begin{abstract}
Background: Young soccer players' injuries are receiving increased interest. The need of adopting injury prevention strategies to reduce financial, social and sport costs is obligated. The main purpose of this study is to analyse clinical characteristics of young soccer players in order to develop specific and effective injury prevention programs. Methods: This observational, transversal study includes 25 young soccer players from Spanish National League. Strength, motor control, flexibility and range of motion characteristics were analysed before the first preseason training. Results: Statistically significant differences were found for hip internal rotation ( $p$ value $=0.001)$, Thomas test $(p$ value $=0.012)$ and ankle dorsiflexion test $(p$ value $=0.009)$ between both sides. Dorsiflexion test showed a positive correlation with the hip internal rotation ROM $(p<0.016)$ and with the triple hop test $(p<0.007)$. The hip internal rotation ROM showed a positive correlation with the Thomas test $(p<0.033)$ and with the single leg squat test ( $\mathrm{p}<$ 0.008). The drop jump test showed a positive correlation with the single leg squat test $(p<0.039)$. Conclusions: Clinical characteristics shown in this study should be taken into account in order to develop specific injury prevention for this specific population. Moreover, data shown in this study can be used as norm values for young soccer semi-professional players in future researches.
\end{abstract}

Key words: Youth sports, soccer, prevention and control.

\section{Introduction}

Soccer is one of the most popular sports worldwide and injuries are the most common reason for unavailability to practice it [1]. Many authors have studied the injury incidence in professional adult soccer players, showing a range of 8.7 to 65.9 injuries per 1,000 h of match exposure [2]. Pfirrmann D et al. found a range of 9.5 to 48.7 per $1,000 \mathrm{~h}$ of match exposure in elite young players aged 16-19 [2]. These data suggest that injuries in elite young players are a problem as important as injuries in adult professional

Corresponding author: Albert Pérez-Bellmunt, Ph.D., full professor, research fields: functional anatomy, fascia, musculoskeletal disorders. Universitat Internacional de Catalunya. footballers or more.

Soccer injuries, aged regardless, have a high social, financial and performance impact. There is a significant association between the number of injuries suffered by the team players and his classification position, showing that injuries affect negatively the team performance [3]. Moreover, injuries have a psychological effect on the player and this could affect his own performance along his sport career [4].

The need of adopting injury prevention strategies to reduce financial, social and sport costs is obligated as shown before. Injury strategies are usually aimed to improve neuromuscular characteristics. Warm up routines have also been described to impact injury prevention and performance in both team and 
individual sports [5, 6]. Decreased strength [7], motor control $[8,9]$, flexibility [10] or range of motion [11] have been shown as possible risk factors to suffer a sport injury. The analysis of these neuromuscular parameters is crucial to develop a specific prevention approach, as lot of professional clubs are doing at this moment [12].

The aim of this study is to analyse the clinical characteristics of a semi-professional youth football team in order to detect some neuromuscular deficits that could help to: (1) understand specifically some injuries incidence and (2) to plan appropriated injury prevention strategies.

\section{Methods}

\subsection{Experimental Approach to the Problem}

This study is an observational study aimed to investigate the clinical characteristics of young soccer players. Clinical characteristics such as motor control, strength, flexibility and range of motion were analysed. A second aim of the study was to discuss about the impact of this clinical characteristics founded with norm values and risk factors shown in other studies. Moreover, such information could be used as young soccer player's reference values.

\subsection{Subjects}

Thirty (30) semi-professional young soccer players aged 17 to 19 from a national Spanish league team participated in this study. The inclusion criteria for the study were (i) not to have been injured during last 3 months and (ii) to have signed (parents in case of subjects under 18) the informed-consent. Five subjects did not meet the first item so finally, 25 subjects completed the study.

This study was approved by the local Ethics Committee and it satisfies the World Medical Association Declaration of Helsinki. Subjects were informed of the benefits and risks of the study prior to signing the informed-consent. Moreover, parents of subjects aged under 18 were equally informed of the study and they also signed the informed-consent.

Subjects mean $( \pm \mathrm{SD})$ height, weight and BMI was $1.78( \pm 0.07) \mathrm{cm}$ (range 1.61-1.92), $68.81( \pm 5.76) \mathrm{kg}$ (range 59.3-81.8) and $21.73 \mathrm{~kg} / \mathrm{m}^{2}( \pm 1.33$ ) (range 19.66-24.02). There were 3 goalkeepers (12\%), 9 defenders (36\%), 5 midfielders (20\%), 4 wings $(16 \%)$ and 4 strikers $(16 \%)$.

\subsection{Procedures}

Data collection was carried out during 2018/2019 preseason, before the first training session. Clinical characteristics as strength, motor control, flexibility and range of motion (ROM) were analysed. Each variable was analysed through scientifically validated screening tests. Tests used to each variable are described below.

\subsubsection{Strength}

\section{(1) Triple Hop for Distance}

This test aims to evaluate the lower limb strength and has been scientifically validated for this purpose. Subject has to perform three consecutive maximal hops forward on the same limb and total distance with each limb being measured with a single meter, as Meierbachtol et al. did [13].

(2) Countermovement Jump

This test aims to evaluate the lower limb strength generated during a countermovement jump (CMJ). Following the methodology used by Balsalobre et al. [14], subject has to perform a maximal vertical jump without using upper limbs. Applicate strength and height are measured with a scientifically validated App named "My Jump 2".

2.3.2 Range of Motion

(1) Dorsiflexion Test

This test aims to evaluate the ankle-dorsiflexion range of motion with a validated IPhone App (named: Dorsiflex App) [15]. Subject has to move into a weight bearing lunge position, to put the device with the screen touching the tibia and to do a maximal ankle-dorsiflexion as Balsalobre et al. [15] proposed in his study. 
(2) Hip Range of Motion

This test aims to evaluate the active hip internal and external rotation [16]. Van Dillen et al. [16] suggested measuring hip ROM by subject lying on the plinth in prone position with the knee flexed 90 degrees having to do hip internal and external rotation. Maximal angle achieved is measured with a common inclinometer.

\subsubsection{Flexibility}

\section{(1) Active Knee Extension (AKE) Test}

This test aims to evaluate hamstring flexibility [17]. Subject lying on the plinth in supine position with 90 degrees of hip flexion has to extend the knee as much as possible and maximal angle achieved is measured with a common goniometer as Hamid et al. [17] did in this study.

(2) Thomas Test

This test aims to evaluate the quadriceps flexibility [18]. Following the Harvey et al. [18] methodology, the subject sits on the end of the plinth; rolls back on to the plinth, and holds both knees to the chest. The subject lowers the tested limb towards the floor. The knee angle difference between initial and final position is measured with a common goniometer [18].

\subsubsection{Motor Control}

(1) Drop Jump Test

This test aims to evaluate the knee valgus-angle during a single leg landing. As Munro et al. [19] did, subject has to land from a $30 \mathrm{~cm}$ height box with a single leg. The maximal knee valgus-angle during the landing is measured using Kinovea software [19].

(2) Single Leg Squat Test

This test aims to evaluate the knee valgus-angle during a single leg squat. Subject has to do a single leg squat and the maximal knee valgus-angle during the task is measured using Kinovea software following the protocol by Munro et al. [19].

(3) Y Balance Test

This test aims to evaluate the neuromuscular control of the lower limb and has been scientifically validated for this purpose. Following the methodology used by Shaffer et al. [20], subject stands on the centre footplate with a single leg. While maintaining single leg stance on one leg, the subject reaches with the other leg limb in the anterior, posteromedial and posterolateral directions. The maximal distance achieved on each direction is measured with a single meter [20].

Moreover, field position, height, weight and BMI were recorded.

Variables were measured bilaterally so the total sample was $n=50$ except for anthropometric measures and countermovement jump, the sample was $n=25$.

\subsection{Statistical Analyses}

SPSS v. 20 was used for the statistical analysis. Quantitative variables and differences are expressed as mean, standard deviation (SD). Level of significance was set at $\alpha=0.05$ and the limits of confidence interval at $95 \%$. The suitability of using parametric or non-parametric test was verified by the Shapiro-Wilk test. The comparison between right and left side was performed using paired simple $t$-test or Wilcoxon test, according to the type of variable used. The correlation analysis was performed using the Pearson correlation coefficient or Spearman's rank correlation coefficient.

\section{Results}

The results were divided in three different parts. Clinical characteristics mean, differences between sides and correlations with significant differences.

\subsection{Clinical Characteristics}

Table 1 shows the mean, standard deviation, minimum and maximum of each variable measured. Results of these analyses and this clinical implication will be commented in the discussion section.

\subsection{Differences between Sides}

On this section, there are just unilateral variables so anthropometrics measures and countermovement jump are not included. Statistically significant differences 
Table 1 Characteristics of the participants.

\begin{tabular}{lllll}
\hline Variable & No. & Minimum & Maximum & Mean \pm SD \\
\hline Height $(\mathrm{m})$ & 25 & 1.61 & 1.92 & $1.78 \pm 0.07$ \\
Weight $(\mathrm{kg})$ & 25 & 59.3 & 81.8 & $68.81 \pm 5.76$ \\
BMI & 25 & 19.66 & 24.02 & $21.73 \pm 1.33$ \\
Dorsiflexión $\left({ }^{\circ}\right)$ & 50 & 28.0 & 50.0 & $37.96 \pm 5.21$ \\
My jump height $(\mathrm{cm})$ & 25 & 27.20 & 46.02 & $33.92 \pm 4.82$ \\
Ake test $\left({ }^{\circ}\right)$ & 50 & 120 & 180 & $139.04 \pm 13.27$ \\
ROM hip Internal rotation $\left({ }^{\circ}\right)$ & 50 & 15 & 55 & $34.66 \pm 9.95$ \\
ROM hip External rotation $\left({ }^{\circ}\right)$ & 50 & 26 & 60 & $41.54 \pm 7.21$ \\
Thomast test $\left({ }^{\circ}\right)$ & 50 & -2 & 10 & $4.10 \pm 2.77$ \\
Drop jump test $\left({ }^{\circ}\right)$ & 48 & 141 & 174 & $158.33 \pm 8.48$ \\
Single leg squat test $\left({ }^{\circ}\right)$ & 50 & 115 & 177 & $154.90 \pm 14.22$ \\
Triple hop (m) & 50 & 5.3 & 7.2 & $6.14 \pm 0.40$ \\
Y balance $(\mathrm{cm})$ & 50 & 73.33 & 96.67 & $84.83 \pm 5.09$ \\
\hline
\end{tabular}

No.: number; SD: standard deviation; cm: centimeter; m: meter; ${ }^{\circ}$ : degrees; kg: kilograms.

Table 2 Difference between sides.

\begin{tabular}{lllll}
\hline Variable & $\begin{array}{l}\text { Right side } \\
\text { mean } \pm \text { SD }\end{array}$ & $\begin{array}{l}\text { Left side } \\
\text { mean } \pm \text { SD }\end{array}$ & $\begin{array}{l}\text { Difference between side } \\
\text { mean } \pm \text { SD }\end{array}$ & $p$ value \\
\hline Dorsiflexión $\left(^{\circ}\right)$ & $37.19 \pm 5.17$ & $39.03 \pm 5.45$ & $1.83 \pm 3.23$ & $0.009^{*}$ \\
Ake test $\left(^{\circ}\right)$ & $138.80 \pm 13.57$ & $139.28 \pm 13.23$ & $0.48 \pm 9.57$ & $0.871^{* *}$ \\
ROM Hip internal rotation $\left(^{\circ}\right)$ & $37.36 \pm 10.25$ & $31.96 \pm 9.06$ & $-5.40 \pm 7.40$ & $0.001^{*}$ \\
ROM hip external rotation $\left(^{\circ}\right)$ & $40.12 \pm 7.44$ & $42.97 \pm 6.81$ & $2.84 \pm 8.59$ & $0.112^{*}$ \\
Thomast test $\left({ }^{\circ}\right)$ & $3.28 \pm 2.52$ & $4.92 \pm 2.81$ & $1.64 \pm 2.95$ & $0.012^{* *}$ \\
Drop jump test $\left({ }^{\circ}\right)$ & $156.96 \pm 9.35$ & $159.71 \pm 7.46$ & $2.75 \pm 10.97$ & $0.232^{*}$ \\
Single leg squat test $\left(^{\circ}\right)$ & $154.08 \pm 13.04$ & $155.72 \pm 15.54$ & $1.64 \pm 19.17$ & $0.673^{*}$ \\
Triple hop $(\mathrm{m})$ & $6.16 \pm 0.42$ & $6.13 \pm 0.39$ & $-0.03 \pm 0.39$ & $0.742^{*}$ \\
Y balance global $(\mathrm{cm})$ & $85.40 \pm 5216$ & $84.26 \pm 5.04$ & $-1.13 \pm 4.97$ & $0.265^{*}$ \\
\hline
\end{tabular}

*t Student test; $* *$ Wilcoxon test; SD: standard deviation; cm: centimeter; ${ }^{\circ}$ : degrees.

were found for HIP internal rotation $\left(\right.$ mean $=5.40^{\circ} ; p$ value $=0.001)$, Thomas test $\left(\right.$ mean $=1.64^{\circ} ; p$ value $=$ 0.012 ) and ankle dorsiflexion (mean $=1.83^{\circ} ; p$ value 0.009 ) between both sides. However, no statistically significant differences were found for AKE test, HIP external rotation, drop jump test, single leg squat test, triple hop test and Y balance test. These results are shown in Table 2. The clinical implication of these data will be discussed in the discussion section.

\subsection{Correlations Analysis}

Dorsiflexion test showed a positive correlation with the ROM Hip Internal rotation $(r=0.347, p<0.016)$ and with the Triple Hop test $(r=0.385 ; p<0.007)$. On the other hand, hip internal rotation ROM showed a positive correlation with the Thomas Test $(r=-0.303$; $p<0.033)$ and with the Single Leg Squat Test $(r=$ $-0.371 ; p<0.008)$. Finally, the Drop Jump Test showed a positive correlation with the Single Leg Squat Test $(r=0.298, p<0.039)$.

\section{Discussion}

\subsection{Clinical Characteristics}

\subsubsection{Strength}

Strength deficit has been described as a potential risk factor to develop sport injuries [7]. The sample of this study had a mean of $33.92 \mathrm{~cm}$ and $6.14 \mathrm{~m}$ on CMJ and triple single-hop test respectively.

Studies have measured countermovement jump height in soccer young players showing means around $38 \mathrm{~cm}$ [21], all of them higher than the value of this 
study. Eliakim et al. [22] found that players who got injured during the season, jumped $36.8 \mathrm{~cm}$ in the preseason screening test. Furthermore, players who did not get injured during the season jumped $39.4 \mathrm{~cm}$ in de preseason screening test [22]. Thus, the sample of this study has poor values in CMJ height and maybe they are at a high risk of injury.

About the triple hop test, values shown in this study agree with the literature. Studies have found values around $6.34 \mathrm{~m}$ for this test [23]. No studies recording injuries in relation with triple single hop test values were found.

CMJ and triple hop test are important and useful measures to detect players at risk of injury and to propose specific injury prevention programs. Values from this study could be used as normal values for future research about this specific population.

\subsubsection{Range of Motion}

Many studies have shown an ankle dorsiflexion deficit as a high risk factor to develop injuries as hamstring injuries [24] or ACL injuries [25]. Mason-Mackay et al. [25], in his systematic review, showed that reduced ankle dorsiflexion could alter landing biomechanics, and this predispose player to injury.

The sample of this study had an average of $37.96^{\circ}$ ankle dorsiflexion. Studies found norm values around $45^{\circ}$ ankle dorsiflexion so the sample of this study is below the average and maybe the subjects have risk of injury [26]. Noronha et al. [27] did an ankle injury risk factor revision and they found that players with an ankle dorsiflexion of $34^{\circ}$ are five times more likely than the others with $45^{\circ}$ ankle dorsiflexion to injure his ankle.

A limited hip range of motion has been described as a risk factor to develop injuries as low back pain [16] or groin pain [11]. The sample of this study has an average of $34.66^{\circ}$ and $41.54^{\circ}$ internal and external rotation respectively.

Regarding the literature, Hogg et al. [28] found an average of $26^{\circ}$ and $35^{\circ}$ internal and external rotation respectively for soccer players, as norm values. However, this study was about adult professional soccer players and it could be different from youth soccer players.

Thus, to measure hip and ankle dorsiflexion range of motion achieve to detect injury risk and to carry on specific injury prevention programs. Moreover, values shown in this study could be served as reference values for future studies in soccer young players where the literature is limited.

\subsubsection{Motor Control}

Nowadays, the evidence suggests that poor or abnormal motor control and lower limb biomechanics during sporting movements such as landing or squatting is the principal contributor to develop injuries as ACL injuries in soccer [29]. Dynamic knee valgus is one of the most accepted modifiable risk factors to have a severe knee injury and it is the most common ACL injury mechanism [29]. Two dimensional video assessment of frontal plane dynamic knee valgus is a useful and validated tool to measure poor valgus control during athletic tasks [19].

In this study, the maximum valgus angle between (1) anterosuperior iliac spine, (2) middle of the patella and (3) ankle point between malleolus was measured. A perfect alignment between these three points, that is to say, an angle of $180^{\circ}$, would be the optimal. However, the sample has an average of $158.33^{\circ}$ and $154.90^{\circ}$ (Drop Jump and SLS test respectively).

On the other hand, Y balance test which aims to evaluate balance and motor control and some studies has demonstrated this validity to predict injuries [20]. This study shows an average of $84.8 \mathrm{~cm}$ on the global $\mathrm{Y}$ balance test score. Some authors have found reference values around $79.76 \mathrm{~cm}$ in military population [20], $100.7 \mathrm{~cm}$ in basketball players [30] and $92.8 \mathrm{~cm}$ in soccer young players [31], which seems very close to values from the sample of this study.

In conclusion, subjects from this study have a poor motor control during landing and single squatting. 
However, Y balance values seem to be next to the norm. As commented before, poor motor control is associated with ACL injury risk so it is crucial to identify poor motor control, for example with these tests, and to work specifically to improve it on specific prevention programs.

\subsubsection{Flexibility}

Thirty-one percent of all soccer injuries are muscle injuries [32]. Many studies have shown that muscle tightness can be a potential risk factor to develop a muscle injury [33]. Specifically, Witvrouw et al. [10] examined 146 male professional soccer players and found that preseason hamstring and quadriceps muscle flexibility testing can identify these players with high risk to develop hamstring and/or quadriceps injuries. On the other hand, Henderson et al. [34] demonstrated that these professional soccer players with lower hamstring flexibility had roughly a $30 \%$ higher risk to develop a hamstring injury.

This study's values showed a mean of $139^{\circ}$ on AKE test and a mean variation from the initial to the final position of $4.1^{\circ}$ on the Thomas test. Studies have found healthy adults norm values of AKE test around $148^{\circ}$ [17], which seems close to this study values. Specifically in soccer, Van Dyk et al. [35] found an average of $168^{\circ}$ on AKE test in adult soccer players. Regarding the study from Van Dyk et al. [35], the sample of this study has poor hamstring flexibility; however, it could be explained because this study sample is young soccer players.

To measure hamstring and quadriceps flexibility is a good way to identify player with high risk of injury and asses to develop specific injury prevention programs.

\subsection{Differences between Sides}

The inter-limb asymmetries have been widely studied within the literature. Range of motion, strength, motor control or flexibility asymmetries have been associated with injury risk [36].

\subsubsection{Strength}

Some authors have studied strength asymmetries as possible risk factors to have an injury or reinjury [37]. Paterno et al. [38] demonstrated that people who have less than $98.5 \%$ of symmetry between sides in a triple hop test have a high risk to reinjure. Kyritis et al. [39] showed that athletes with a difference between sides > $10 \%$ in different hop tests are four times more likely to reinjure. Haitz et al. [40] showed symmetry norm values of triple hop test in athletes around $98.6 \%$. In the triple hop test for distance, the sample of this study had a difference between sides of $0.03 \pm 0.39$ [mean \pm SD] so they are at good strength symmetry parameters.

To evaluate strength asymmetries is a good way to identify risk factors that should be worked on specific injury prevention programs.

\subsubsection{Range of Motion}

Nguyen et al. [41] studied hip ROM asymmetries in young females soccer players. They concluded that asymmetries could cause an altered activation pattern on hip muscles [41]. Thus, hip ROM asymmetries could cause a failure on hip stabilization and this could have an implication on ACL injury. Hip internal rotation ROM significant differences between sides were observed in this study ( $p$ value $=0.001$ ), but no differences on hip external rotation were observed.

On the other hand, ankle dorsiflexion ROM asymmetries have demonstrated its importance on injury prevention within the literature [15]. Teyhen et al. [42] observed that people with $>6.5^{\circ}$ asymmetry between sides on ankle dorsiflexion are four times more likely to develop an injury. Significant differences ( $p$ value 0.009) between sides were observed on ankle dorsiflexion range of motion in this study. The difference average was $1,83^{\circ}$, it means a $4.82 \%$ of asymmetry.

ROM asymmetries could cause altered muscle activation patterns so it must be assessed to develop specific injury prevention programs. Regarding the data of this study, young soccer players should improve hip and ankle ROM and symmetry as part of injury prevention, specifically hip internal rotation 
ROM and ankle dorsiflexion.

\subsubsection{Motor Control}

Dai et al. [43] and Paterno et al. [44] studied the knee kinetics asymmetries after anterior cruciate ligament reconstruction showing that it was a possible explication of the high reinjury ratio after de return to play (ranging 6\% to 27\%). Fortunately, the sample of this study did not show statistical differences between sides in any of the motor control test.

To evaluate the motor control symmetry allows identifying players with high risk of injury or reinjury so it should be part of the specific injury prevention programs.

\subsubsection{Flexibility}

Flexibility asymmetries have been negatively associated with lower limb injury within the literature $([37,45])$. Soccer players usually favour one particular leg for kicking, passing or jumping. This could cause flexibility imbalance which is believed to predispose players to injury [46].

This study found significant differences between sides in quadriceps flexibility (Thomas test) $(p$ value $=$ 0.012). However, no differences were observed on hamstring flexibility by the AKE test. Regarding the data from this study, young soccer player's flexibility symmetry should be measured and worked specifically.

In conclusion, injury prevention programs should keep in mind possible asymmetries. It is really important to evaluate symmetries between sides and to work it specifically on injury prevention.

\subsection{Correlation Analysis}

Dorsiflexion showed a positive correlation with the Triple Hop $(r=0.385 ; p<0.007)$. A good ankle dorsiflexion range of motion is needed to generate force against the ground while the player is hopping. This correlation suggests that if somebody wants to improve his hopping strength, he must have an optimal ankle dorsiflexion range of motion. To have a limited ankle dorsiflexion could avoid a hop strength improvement. In conclusion, to improve the lower limb functional strength, a good ankle dorsiflexion is necessary.

The Hip Internal rotation ROM showed a positive correlation with the Thomas Test $(r=-0.303 ; p<$ 0.033). This correlation suggests that hip internal rotation ROM could be influenced by quadriceps flexibility. It is important to keep in mind quadriceps flexibility to improve hip range of motion on a specific prevention program.

The Drop Jump Test showed a positive correlation with the Single Leg Squat Test $(r=0.298, p<0.039)$. Both of them measure the same so it is normal they correlate. However, this correlation is useful to say that only one of them is enough to evaluate the dynamic valgus during a specific task. Maybe the drop jump is a more functional task so it is proposed to choose it.

\subsection{Limitations}

The principal limitation of this study is the short size of the sample. It would be interesting to know if values obtained from this study are the same with a larger size. Moreover, in this study there is no follow up because it is a cross-sectional study. It is a limitation and it would be interesting to know if values change throughout the preseason period.

\section{Conclusions}

This study aimed to evaluate clinical characteristics from young soccer players and to discuss about his implication on injury prevention. In order to develop specific and effective injury prevention programs, it is necessary to measure parameters as strength, flexibility, motor control or range of motion. If it is not measured, the injury prevention is widely unspecific and it is not working by the time. As commented before, soccer is an asymmetrical sport. Thus, to identify asymmetries is very interesting on soccer injury prevention and it gives crucial information to develop specific programs. On the 
other hand, in order to improve some parameters such as functional strength, range or motion or dynamic knee valgus control, correlations shown in this study should be kept in mind.

Finally, this study showed specific values for semi-professional youth soccer players and injury risk associated to this data have been widely explained. Coaches, athletes and researchers may use it to compare with their own sample or soccer players. Moreover, youth soccer teams physical trainers and physiotherapists may develop specific injury prevention programs focussing on neuromuscular deficits shown in this study.

\section{Acknowledgments}

Authors are grateful to soccer players involved in this investigation. Furthermore, authors are particularly grateful to Damm Football Club for allowing us to develop the investigation. No grant support was provided for this study. The results of this study do not constitute endorsement of the product by the authors or by the NSCA.

\section{References}

[1] Ekstrand, J., Hägglund, M., and Waldén, M. 2011. "Injury Incidence and Injury Patterns in Professional Football-The UEFA Injury Study Injury Incidence and Injury Patterns in Professional Football-The UEFA Injury Study.” Br J Sports Med. 45 (7): 533-8.

[2] Pfirrmann, D., Herbst, M., Ingelfinger, P., Simon, P., and Tug, S. 2016. "Analysis of Injury Incidences in Male Professional Adult and Elite Youth Soccer Players: A Systematic Review." J Athl Train. 51 (5): 410-24.

[3] Hägglund, M., Waldén, M., Magnusson, H., Kristenson, K., Bengtsson, H., and Ekstrand, J. 2013. "Injuries Affect Team Performance Negatively in Professional Football: An 11-Year Follow-up of the UEFA Champions League Injury Study." Br J Sports Med. 47 (12): 738-42.

[4] Zafra, A. O., and Toro, E. O. 2010. "Efectos de las lesiones sobre las variables psicológicas en futbolistas juveniles." Rev Latinoam Psicol. 42 (2): 265-77.

[5] Neiva, H. P., Marques, M. C., Barbosa, T. M., Izquierdo, M., and Marinho, D. A. 2014. "Warm-Up and Performance in Competitive Swimming." Sport Med. 44 (3): 319-30.

[6] Silva, L. M., Neiva, H. P., Marques, M. C., Izquierdo, M., and Marinho, D. A. 2018. "Effects of Warm-Up, Post-Warm-Up, and Re-Warm-Up Strategies on Explosive Efforts in Team Sports: A Systematic Review." Sport Med. 48 (10): 2285-99.

[7] Lauersen, J. B., Bertelsen, D. M., and Andersen, L. B. 2014. "The Effectiveness of Exercise Interventions to Prevent Sports Injuries: A Systematic Review and Meta-Analysis of Randomised Controlled Trials." $\mathrm{Br} \mathrm{J}$ Sports Med. 48 (11): 871-7.

[8] Hides, J. A., and Stanton, W. R. 2014. "Can Motor Control Training Lower the Risk of Injury for Professional Football Players?" Med Sci Sport Exerc. 46 (4): 762-8.

[9] Fransz, D. P., Huurnink, A., Kingma, I., de Boode, V. A., Heyligers, I. C., and van Dieën, J. H. 2018. "Performance on a Single-Legged Drop-Jump Landing Test Is Related to Increased Risk of Lateral Ankle Sprains among Male Elite Soccer Players: A 3-Year Prospective Cohort Study." Am J Sports Med. 46 (14): 3454-62.

[10] Witvrouw, E., Danneels, L., Asselman, P., D’Have, T., and Cambier, D. 2003. "Muscle Flexibility as a Risk Factor for Developing Muscle Injuries in Male Professional Soccer Players." Am J Sports Med. 31 (1): 41-6.

[11] Tak, I., Glasgow, P., Langhout, R., Weir, A., Kerkhoffs, G., and Agricola, R. 2016. "Hip Range of Motion Is Lower in Professional Soccer Players with Hip and Groin Symptoms or Previous Injuries, Independent of Cam Deformities." Am J Sports Med. 44 (3): 682-8.

[12] McCall, A., Carling, C., Nedelec, M., Davison, M., Le Gall, F., Berthoin, S., et al. 2014. "Risk Factors, Testing and Preventative Strategies for Non-contact Injuries in Professional Football: Current Perceptions and Practices of 44 Teams from Various Premier Leagues.” Br J Sports Med. 48 (18): 1352-7.

[13] Meierbachtol, A., Rohman, E., Paur, E., Bottoms, J., and Tompkins, M. 2017. "Quantitative Improvements in Hop Test Scores after a 6-Week Neuromuscular Training Program." Sport Heal A Multidiscip Approach 9 (1): 22-9.

[14] Balsalobre-Fernández, C., Glaister, M., and Lockey, R. A. 2015. "The Validity and Reliability of an iPhone App for Measuring Vertical Jump Performance.” J Sports Sci. 33 (15): 1574-9.

[15] Balsalobre-Fernández, C., Romero-Franco, N., and Jiménez-Reyes, P. 2018. "Concurrent Validity and Reliability of an iPhone App for the Measurement of Ankle Dorsiflexion and Inter-Limb Asymmetries." $J$ Sports Sci. 2018 Jul 2;00(00): 1-5.

[16] Van Dillen, L. R., Bloom, N. J., Gombatto, S. P., and Susco, T. M. 2008. "Hip Rotation Range of Motion in People with and without Low Back Pain Who Participate in Rotation-Related Sports." Phys Ther Sport 9 (2): 
$72-81$.

[17] Hamid, M. S. A., Ali, M. R. M., and Yusof, A. 2013. "Interrater and Intrarater Reliability of the Active Knee Extension (AKE) Test among Healthy Adults." J Phys Ther Sci. 25 (8): 957-61.

[18] Harvey, D. 1998. "Assessment of the Flexibility of Elite Athletes Using the Modified Thomas Test." Br J Sports Med. 32 (1): 68-70.

[19] Munro, A., Herrington, L., and Carolan, M. 2012. "Reliability of 2-Dimensional Video Assessment of Frontal-Plane Dynamic Knee Valgus during Common Athletic Screening Tasks." J Sport Rehabil. 21 (1): 7-11.

[20] Shaffer, S. W., Teyhen, D. S., Lorenson, C. L., Warren, R. L., Koreerat, C. M., Straseske, C. A., et al. 2013. "Y-Balance Test: A Reliability Study Involving Multiple Raters.” Mil Med. 178 (11): 1264-70.

[21] Bekris, E., Pidoulas, G., Pidoulas, P., Gissis, I., Katis, A., and Komsis, S. 2018. "Examination of Physical Fitness Parameters between Professional and Amateur Greek Soccer Players during the Transition Period." J Strength Cond Res. 1-6.

[22] Eliakim, E., Doron, O., Meckel, Y., Nemet, D., and Eliakim, A. 2018. "Pre-season Fitness Level and Injury Rate in Professional Soccer-A Prospective Study." Sport Med Int Open 2 (3): E84-90.

[23] Myers, B. A., Jenkins, W. L., Killian, C., and Rundquist, P. 2014. "Normative Data for Hop Tests in High School and Collegiate Basketball and Soccer Players." Int J Sports Phys Ther. 9 (5): 596-603.

[24] Gabbe, B. J., Bennell, K. L., Finch, C. F., Wajswelner, H., and Orchard, J. W. 2006. "Predictors of Hamstring Injury at the Elite Level of Australian Football." Scand J Med Sci Sport 16 (1): 7-13.

[25] Mason-Mackay, A. R., Whatman, C., and Reid, D. 2017. "The Effect of Reduced Ankle Dorsiflexion on Lower Extremity Mechanics during Landing: A Systematic Review." J Sci Med Sport 20 (5): 451-8.

[26] Malliaras, P., Cook, J. L., and Kent, P. 2006. "Reduced Ankle Dorsiflexion Range May Increase the Risk of Patellar Tendon Injury among Volleyball Players." J Sci Med Sport 9 (4): 304-9.

[27] de Noronha, M., Refshauge, K. M., Herbert, R. D., Kilbreath, S. L., and Hertel, J. 2006. "Do Voluntary Strength, Proprioception, Range of Motion, or Postural Sway Predict Occurrence of Lateral Ankle Sprain?” Br J Sports Med. 40 (10): 824-8.

[28] Hogg, J. A., Schmitz, R. J., Nguyen, A.-D., and Shultz, S. J. 2018. "Passive Hip Range-of-Motion Values across Sex and Sport." J Athl Train. 53 (6): 560-7.

[29] Hewett, T. E., Myer, G. D., Ford, K. R., Heidt, R. S., Colosimo, A. J., McLean, S. G., et al. 2005. "Biomechanical Measures of Neuromuscular Control and
Valgus Loading of the Knee Predict Anterior Cruciate Ligament Injury Risk in Female Athletes: A Prospective Study." Am J Sports Med. 33 (4): 492-501.

[30] Plisky, P. J., Rauh, M. J., Kaminski, T. W., and Underwood, F. B. 2006. "Star Excursion Balance Test as a Predictor of Lower Extremity Injury in High School Basketball Players." J Orthop Sport Phys Ther. 36 (12): 911-9.

[31] Smith, J., DePhillipo, N., Azizi, S., McCabe, A., Beverine, C., Orendurff, M., et al. 2018. "The Lower Extremity Grading System (Legs) to Evaluate Baseline Lower Extremity Performance in High School Athletes." Int $J$ Sports Phys Ther. 13 (3): 401-9.

[32] Hernández-Sanchez, S., Korakakis, V., Malliaropoulos, N., and Moreno-Perez, V. 2018. "Validation Study of the Functional Assessment Scale for Acute Hamstring Injuries in Spanish Professional Soccer Players." Clin Rehabil. 026921551881554.

[33] Liu, H., Garret, W. E., Moorman, C. T., and Yu, B. 2012. "Injury Rate, Mechanism, and Risk Factors of Hamstring Strain Injuries in Sports: A Review of the Literature." $J$ Sport Heal Sci. 1 (2): 92-101.

[34] Henderson, G., Barnes, C. A., and Portas, M. D. 2010. "Factors Associated with Increased Propensity for Hamstring Injury in English Premier League Soccer Players." J Sci Med Sport 13 (4): 397-402.

[35] van Dyk, N., Farooq, A., Bahr, R., and Witvrouw, E. 2018. "Hamstring and Ankle Flexibility Deficits Are Weak Risk Factors for Hamstring Injury in Professional Soccer Players: A Prospective Cohort Study of 438 Players Including 78 Injuries.” Am J Sports Med. 46 (9): 2203-10.

[36] Ebert, J. R., Edwards, P., Yi, L., Joss, B., Ackland, T., Carey-Smith, R., et al. 2018. "Strength and Functional Symmetry Is Associated with Post-Operative Rehabilitation in Patients Following Anterior Cruciate Ligament Reconstruction." Knee Surgery, Sport Traumatol Arthrosc. 26 (8): 2353-61.

[37] Grygorowicz, M., Kubacki, J., Pilis, W., Gieremek, K., and Rzepka, R. 2010. "Selected Isokinetic Tests in Knee Injury Prevention.” Biol Sport 27 (1): 47-51.

[38] Paterno, M. V., Huang, B., Thomas, S., Hewett, T. E., and Schmitt, L. C. 2017. "Clinical Factors That Predict a Second ACL Injury after ACL Reconstruction and Return to Sport: Preliminary Development of a Clinical Decision Algorithm." Orthop J Sport Med. 5 (12): 232596711774527.

[39] Kyritsis, P., Bahr, R., Landreau, P., Miladi, R., and Witvrouw, E. 2016. "Likelihood of ACL Graft Rupture: Not Meeting Six Clinical Discharge Criteria before Return to Sport Is Associated with a Four Times Greater Risk of Rupture.” Br J Sports Med. 50 (15): 946-51.

[40] Haitz, K., Shultz, R., Hodgins, M., and Matheson, G. O. 
2014. "Test-Retest and Interrater Reliability of the Functional Lower Extremity Evaluation.” J Orthop Sport Phys Ther. 44 (12): 947-54.

[41] Nguyen, A.-D., Zuk, E. F., Baellow, A. L., Pfile, K. R., DiStefano, L. J., and Boling, M. C. 2017. "Longitudinal Changes in Hip Strength and Range of Motion in Female Youth Soccer Players: Implications for ACL Injury, A Pilot Study." J Sport Rehabil. 26 (5): 358-64.

[42] Teyhen, D. S., Shaffer, S. W., Butler, R. J., Goffar, S. L., Kiesel, K. B., Rhon, D. I., et al. 2015. "What Risk Factors Are Associated with Musculoskeletal Injury in US Army Rangers? A Prospective Prognostic Study." Clin Orthop Relat Res. 473 (9): 2948-58.

[43] Dai, B., Butler, R. J., Garrett, W. E., Queen, R. M. 2014. "Using Ground Reaction Force to Predict Knee Kinetic
Asymmetry Following Anterior Cruciate Ligament Reconstruction." Scand J Med Sci Sports 24 (6): 974-81.

[44] Paterno, M. V., Schmitt, L. C., Ford, K. R., Rauh, M. J., Myer, G. D., and Hewett, T. E. 2011. "Effects of Sex on Compensatory Landing Strategies Upon Return to Sport after Anterior Cruciate Ligament Reconstruction." $J$ Orthop Sport Phys Ther. 41 (8): 553-9.

[45] Daneshjoo, A., Rahnama, N., Mokhtar, A. H., and Yusof, A. 2013. "Bilateral and Unilateral Asymmetries of Isokinetic Strength and Flexibility in Male Young Professional Soccer Players." J Hum Kinet. 36 (1): 45-53.

[46] Rahnama, N., Lees, A., and Bambaecichi, E. 2005. "A Comparison of Muscle Strength and Flexibility between the Preferred and Non-preferred Leg in English Soccer Players." Ergonomics 48 (11-14): 1568-75. 